Letters to the Editor

\title{
Electrochemiluminescence Detection of Primary Amines Using Tris(bipyridine)ruthenium(III) after Derivatization with Divinylsulfone
}

\author{
Kazuo UchiKura*, Makoto Kirisawa* and Atsusi SugII** \\ *College of Pharmacy, Nihon University, Narashinodai, Funabashi 274, Japan \\ **Faculty of Pharmaceutical Sciences, Kumamoto University, Oe-honmachi, Kumamoto 862, Japan
}

Keywords Electrochemiluminescence, primary amine, divinylsulfone, tris(bipyridine)ruthenium(II), derivatization

\begin{abstract}
Aliphatic primary amines are industrial chemicals with a wide variety of applications. For the determination of these substances, HPLC has recently been used; it has several advantages over other analytical methods, including high selectivity and sensitivity. On the other hand, an electrochemiluminescence (ECL) method has been developed as a highly sensitive method for HPLC detection..$^{1-3}$ However, there is still no established methodology for the determination of aliphatic primary amines.

The Tris(bipyridine)ruthenium(II) $\left(\mathrm{Ru}(\mathrm{bpy})_{3}{ }^{2+}\right) \mathrm{ECL}$ system is useful for a selective, sensitive determination of oxalates $^{4,5}$, indoles ${ }^{1,6}$, and trialkylamines ${ }^{2,7}$ in biological and pharmaceutical samples. We previously reported that by using this system alicyclic tertiary amines ${ }^{8}$ were detectable at the pmol level, althouth the CL intensity of aliphatic primary amines was very low compared with that of the tertiary amines; and they could only be detected at a level of about 1000-times lower than that of tertiary amines. ${ }^{7}$

In this paper we discuss the CL detection of some primary amines using a cycloaddition reaction of the amines with divinyl sulfone (DVS) caused by electrogenerated $\mathrm{Ru}(\mathrm{bpy})_{3}{ }^{3+}$. Furthermore, precolumn derivatization HPLC of the amines using LC postcolumn reaction detection with this CL system is described.
\end{abstract}

\section{Experimental}

\section{Chemicals and standard solution}

$\mathrm{Ru}$ (bpy) ${ }_{3} \mathrm{Cl}_{2}$ was obtained from Sigma Chemical Co. (St. Louis, MO, USA) and used without further purification. DVS was obtained from Aldrich Chemical Co. Inc. (WI, USA). Sample amines were obtained from Tokyo Kasei Co., Ltd. (Tokyo, Japan). All of the other chemicals and solvents were of guaranteed grade. Water was deionized and distilled using a hard-glass vessel. A stock standard solution ( $2 \mathrm{mM}$ ) of amines was prepared by dissolving them in water-methanol $(1: 1$, $\mathrm{v} / \mathrm{v}$ ). A working solution was prepared by appropriate dilution of the stock solution before use.

\section{Apparatus and HPLC conditions}

The HPLC system comprised a PSU-2.5T micro pump (Seishin Pharm., Tokyo, Japan), a Rheodyne 7125 sample injector with a sample volume of $10 \mu 1$ (Cotati, CA, USA), a home-made electrochemical reactor ${ }^{9}$, an HA-101 potentio-galvanostat (Hokuto Denko, Japan), an LC30-DPC10 chemiluminescence detector (JEOL, Japan) and a U-228 Unicorder (Pantos, Tokyo). The electrochemical oxidation mode was used for controlledcurrent electrolysis; the current was maintained at $80 \mu \mathrm{A}$. The column used was an L-column ODS (150×4.6 mm i.d., Kagakuhin Kensa Kyokai, Japan) which was maintained at $50^{\circ} \mathrm{C}$ by a Minder Ace water bath (Taiyo Scientific, Japan). Figure 1 is a schematic diagram of the present system. The eluent comprised acetonitrile and $10 \mathrm{mM} \mathrm{KH}_{2} \mathrm{PO}_{4}(40: 60, \mathrm{v} / \mathrm{v})$; the flow rate was $1.0 \mathrm{ml} \mathrm{m^{-1 }}$. The reagent solution was prepared by dissolving $\mathrm{Ru}$ (bpy) ${ }_{3} \mathrm{Cl}_{2}$ to $0.30 \mathrm{mM}$ in $10 \mathrm{mM} \mathrm{H}_{2} \mathrm{SO}_{4}$; the flow rate was $0.3 \mathrm{ml} \mathrm{min}{ }^{-1}$. This reagent solution was

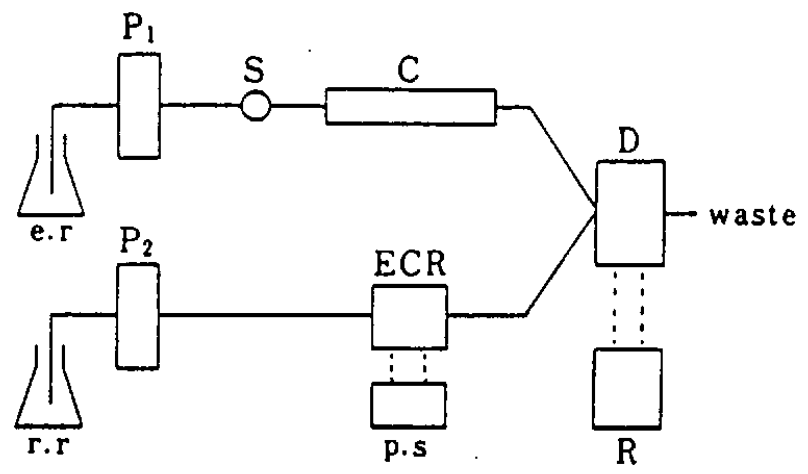

Fig. 1 Schematic flow diagram of high-performance liquid chromatography with electrochemiluminescence detection: e.r, eluent reservoir; r.r, reagent reservoir; $P 1$ and $P 2$, pumps; $\mathrm{S}$, sample injector; $\mathrm{C}$, column; ECR, electrochemical reactor; p.s, ptentio-galvanostat; $\mathrm{D}$, detector; $\mathrm{R}$, recorder. 
stable for two months.

\section{Derivatization procedure}

The derivatization reagent solution (1 M) was DVS dissolved in methanol. Into a tube was added $5 \mathrm{ml}$ of a mixture of $50 \mathrm{mM}$ borate buffer (pH 8.0) and methanol $(1: 1, v / v)$. Two hundred microliters of $1 \mathrm{M}$ DVS methanol solution was combined with $10 \mu \mathrm{l}$ of sample amines and then mixed with a vortex mixer. After the reaction mixture was allowed to stand at $50^{\circ} \mathrm{C}$ for $15 \mathrm{~min}$ and then cooled to room temperature, a $10 \mu \mathrm{l}$ aliquot was injected directly into the HPLC or FIA system.

\section{Results and Discussion}

\section{Derivatization}

It has been shown by Lawson \& Reid ${ }^{10}$ and Bellart ${ }^{11}$ that primary amines treated with DVS form 1,4-thiazane-1,1-dioxide derivatives (DVS-amines), although the yield is low, ranging from 26 to $76 \%$. We previously reported the generation of chemiluminescence by the reaction of alicyclic tertiary amines with $\mathrm{Ru}(\mathrm{bpy}) \mathrm{3}_{3}{ }^{2+8}$ It was observed that these DVS-amines generated marked chemiluminescence.

The conditions of the derivatization reaction, such as the temperature, $\mathrm{pH}$, DVS concentration and heating time, were examined in terms of the conversion of primary amines to tertiary amines. The amount of DVSamines formed is considered to be proportional to their ECL intensity. First, because the Mickel-type reaction in Scheme 1 was accelerated in the presense of a base, we examined the role of the $\mathrm{pH}$ in the formation of DVS derivatives. The formation of DVS-amines increased with increasing $\mathrm{pH}$; the maximal formation occurred at pH 8.0, after which it decreased. Second, the effect of the temperature on the formation of DVS derivatives was investigated. It was found that a higher temperature accelerated the reaction rate. Finally, the effect of the DVS concentration on the formation of DVS-amines was examined. Within the range $40-80 \mathrm{mM}$, formation was constant. Therefore, the derivatization conditions employed were $40 \mathrm{mM}$ DVS, $50^{\circ} \mathrm{C}$ and $15 \mathrm{~min}$. The yield of DVS-amine for propylamine was above $98 \%$.

\section{Detection of DVS-amines}

The relative electrochemiluminescence intensity of DVS-amines of the primary amines is shown in Table 1. The alkyl chain length had an effect on the intensity, as did the branching. An increase in the ECL intensity of DVS derivatives occurred in the following order: straight chain<branched chain<alicyclic type. ECL intensity increased as the $\mathrm{pH}$ increased from 2.5 to 7.0 , but decreased at higher $\mathrm{pH}$.

\section{Separation of DVS derivatives}

The DVS derivatives were separated by HPLC using postcolumn chemiluminescence detection (Fig. 2).

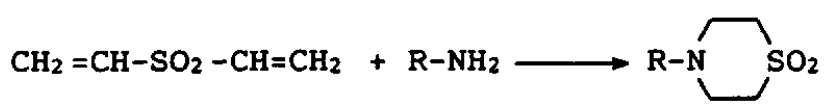

Scheme 1

Table 1 Electrochemiluminescence intensity of DVS derivatives

\begin{tabular}{lcc}
\hline \multicolumn{1}{c}{ Amine } & $\begin{array}{c}\text { ECL intensity } \\
\text { (peak height/mm) }\end{array}$ & $\begin{array}{c}\text { Relative ECL } \\
\text { intensity }\end{array}$ \\
\hline Methylamine & 15.0 & 1.0 \\
Ethylamine & 34.0 & 2.3 \\
Propylamine & 66.0 & 4.4 \\
Butylamine & 74.0 & 4.9 \\
Pentylamine & 66.0 & 4.4 \\
Hexylamine & 63.5 & 4.2 \\
Heptylamine & 63.4 & 4.4 \\
Isobutylamine & 151.0 & 10.1 \\
$t$-Butylamine & 59.0 & 3.9 \\
Isopropylamine & 50.0 & 3.3 \\
$s$-Butylamine & 104.0 & 6.9 \\
2-Aminopentane & 128.0 & 8.5 \\
3-Aminopentane & 1670.0 & 111.3 \\
4-Heptylamine & 1909.0 & 127.3 \\
Cyclopropylamine & 104.1 & 6.9 \\
Cyclopentylamine & 880.0 & 58.7 \\
Cyclohexylamine & 213.9 & 14.2 \\
Cycloheptylamine & 690.0 & 46.0 \\
\hline
\end{tabular}

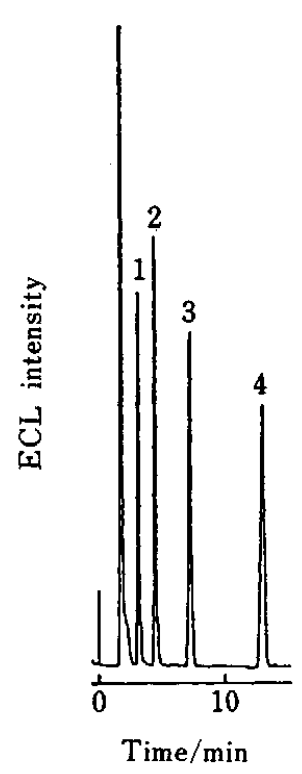

Fig. 2 Separation of DVS derivatives by high-performance liquid chromatography with electrochemiluminescence detection. Peaks: 1 , propylamine; 2 , butylamine; 3 , pentylamine; 4, hexylamine. HPLC conditions: eluent, $10 \mathrm{mM}$ $\mathrm{KH}_{2} \mathrm{PO}_{4}-\mathrm{CH}_{3} \mathrm{CN}(6: 4, \mathrm{v} / \mathrm{v})$, flow rate, $1.0 \mathrm{ml} \mathrm{min}{ }^{-1}$; column, L-column ODS ( $150 \times 4.6 \mathrm{~mm}$ i.d.); reagent solution, $0.3 \mathrm{mM}$ $\mathrm{Ru}$ (bpy) ${ }_{3} \mathrm{Cl}_{2}$ in $10 \mathrm{mM} \mathrm{H}_{2} \mathrm{SO}_{4}$, flow rate, $0.3 \mathrm{ml} \mathrm{min}^{-1}$; oxidation current, $80 \mu \mathrm{A}$. 
Each alkylamine was clearly separated, and the detection limit was about $30 \mathrm{pmol}$ for propylamine and $1 \mathrm{pmol}$ for 3-aminopentane.

In conclusion, the derivatization reaction rapidly produced a high yield under conditions as mild as $\mathrm{pH} 8$ and $50^{\circ} \mathrm{C}$. The DVS derivatives were sensitively detected using tris(2,2'-bipyridine)ruthenium(III) chemiluminescence. This approach should prove to be useful for the selective, sensitive detection of primary amines, such as amino acids, polyamines and other biological amines. Furthermore, the combined use of HPLC for postcolumn derivatization detection is expected to be a specific, simple and sensitive method for the determination of compounds for a wide variety of complex biological samples. Furthermore, postcolumn derivatization HPLC combined with this reaction should be a useful, selective and sensitive method for the detection of primary amines.

\section{References}

1. K. Uchikura and M. Kirisawa, Anal. Sci, 7, 971 (1991).

2. J. B. Noffsinger and N. D. Danielson, J. Chromatogr., 387, 520 (1987).

3. M. A. Targove and N. D. Danielson, J. Chromatogr. Sci., 28, 505 (1990).

4. I. Rubinstein and A. J. Bard, J. Am. Chem. Soc., 103, 512 (1981).

5. K. Uchikura, Bunseki Kagaku, 39, 323 (1990).

6. K. Uchikura and M. Kirisawa, Chem. Lett., 1991, 1373.

7. J. B. Noffsinger and N. D. Danielson, Anal. Chem., 59, 865 (1987).

8. K. Uchikura and M. Kirisawa, Anal. Sci., 7, 803 (1991).

9. K. Uchikura, Anal. Sci., 6, 351 (1990).

10. W. E. Lawson and E. E. Reid, J. Am. Chem. Soc., 47, 2821 (1925).

11. A. C. Bellaart, Recueil, 81, 156 (1962).

(Received September 8, 1992)

(Accepted November 24, 1992) 